\title{
A new species of Sitochroa Hübner, 1825 (Lepidoptera, Crambidae, Pyraustinae) from Iran, with taxonomic notes on the genus
}

\author{
Helen Alipanah ${ }^{1}$, Tobias Malm², Jan Asselbergs ${ }^{3}$ \\ 1 Iranian Research Institute of Plant Protection (IRIPP), Agricultural Research, Education and Extension Organization \\ (AREEO),Tehran; e-mail: alipanah@iripp.ir; halipanah@gmail.com \\ 2 Department of Zoology, Swedish Museum of Natural History, Stockholm, Sweden; email: tobias.malm@nrm.se \\ 3 Neerland 20,4614 GD Bergen op Zoom, The Netherlands; e-mail: jef.asselbergs@hetnet.nl
}

http://zoobank.org/AFE0F1E9-9E4B-4E55-9A64-73FA955F1895

Received 5 December 2019; accepted 3 February 2020; published: 14 April 2020

Subject Editor: Bernard Landry.

\begin{abstract}
Sitochroa urmiensis sp. nov. is described based on a single male collected in West Azarbaijan Province, Iran. Sitochroa palealis (Denis \& Schiffermüller, 1775) is considered as a senior synonym of Loxostege farsalis Amsel, 1950 syn. nov. Loxostege malekalis Amsel, 1950 is transferred to the genus Sitochroa Hübner, as S. malekalis (Amsel, 1950) comb. nov. And the hitherto unknown female of S. malekalis is described and illustrated.
\end{abstract}

\section{Introduction}

The subfamily Pyraustinae with 1175 species in 173 genera (Nuss et al. 2003-2019), is currently divided into three tribes, namely Euclastini Popescu-Gorj and Constantinescu, 1977, Portentomorphini Amsel, 1956 and Pyraustini Meyrick, 1890 (Mally et al. 2019). Within the tribe Pyraustini, the two Holarctic genera Sitochroa Hübner and Loxostege Hübner constitute a monophyletic clade, with Achyra Guenée as their sister group (Chen et al. 2019; Mally et al. 2019). According to Mally et al. (2019), the monophyly of Sitochroa+Loxostege is supported by five homoplastic apomorphies, of which four are abdominal and genitalia characters. These two genera can easily be distinguished from each other by the shape of the ventral clasper of valva and of the phallus in male genitalia. In Sitochroa, the clasper has two basally curved hook-like processes, and a strongly sclerotized process extending from the distal end of phallus; whereas in Loxostege the clasper is uniramous and the phallus is simple (Munroe 1976).

The genus Sitochroa, with 10 known species worldwide (Nuss et al. 2003-2019), was erected by Hübner (1825) to accommodate the type species, Pyralis palealis (Denis \& Schiffermüller, 1775). The genus is represented in Iran by S. palealis, S. straminealis (Hampson, 1900), and S. verticalis (Linnaeus, 1758) (Lederer 1869; Christoph 1876; Amsel 1961). In addition, Amsel (1950) described two Loxostege species, L. farsalis and L. malekalis, collected from Fars (Komehr), and Sistan and Baluchestan (Takht-e Malek) Provinces of Iran, respectively. In both species, the clasper is bifurcate and the phallus has a peculiar and relatively long distal process. These two Loxostege species are here considered as new members of the genus Sitochroa, of which L. farsalis is placed in synonymy with S. palealis. Furthermore, a new Iranian species of Sitochroa is described and illustrated. 


\section{Methods}

Genitalia were dissected and prepared using the methods described by Clarke (1941) and Robinson (1976). Photographs were taken with a digital camera DSC-F717 and a Dino-Eye microscope eyepiece camera. The software Combine ZP was used to stack some of the images. The terminology follows that of Kristensen (2003) and Slamka (2013).

All specimens examined in the current study are deposited in the Hayk Mirzayans Insect Museum (HMIM), Iranian Research Institute of Plant Protection (IRIPP) with the following exceptions: the type specimens of L. farsalis are deposited at the Swedish Museum of Natural History (NHRS), and the only male specimen of L. malekalis collected in Kopet Dagh is in the private collection of the third author.

\section{Taxonomy}

Sitochroa urmiensis Alipanah, sp. nov.

http://zoobank.org/55E14266-F078-455C-9CDC-1041F696AE45

Figs $1 \mathrm{~A}, \mathrm{~B}, 2 \mathrm{~A}-\mathrm{C}, 3 \mathrm{~A}, \mathrm{C}$

Material examined. Holotype, ổ, Iran, WeSt ĀZARBĀIJĀN Prov[INCE]: Orumiyeh, Ghāsemlu, 10.vi.1975, Abāi leg. (genitalia preparation No. HA-2457, HMIM).

Diagnosis. In external appearance, especially in wing pattern, $S$. urmiensis is close to S. palealis (in populations with weakly expressed wing patterns) and less so to $S$. straminealis. However, the medial line of the hindwing is more visible in $S$. urmiensis sp. nov. compared with $S$. palealis (Figs 1A-F, 8C, D). There is no noticeable difference among the three above mentioned species in the shape of the head and the labial palpi (Figs 3A-D, 5A-D).

Based on the male genitalia, the new species is more similar to $S$. straminealis than to any other known species of the genus (Fig. 2A-F). These two species resemble each other mainly in the shape of the distal half of the valvae; the width of the uncus in relation to the width of the valvae; the rounded sinus between the prongs of the clasper; the presence of an inwardly pointed trapezoidal blade-like structure above the clasper; and a thorn-like or needle-shaped distal process in the phallus. Furthermore, in both species the cornuti consist of a bundle of elongate thorns and a finger-shaped process that is wavy in $S$. urmiensis sp. nov. whereas it is straight in $S$. straminealis (Fig. 2A, C, D, F).

However, the male genitalia of these two species differ as follows: the tip of the uncus is semi-triangular in S. urmiensis sp. nov. and dome-shaped in S. straminealis (Fig. 2A, D); the clasper prongs in $S$. urmiensis sp. nov. are longer than those of $S$. straminealis (Fig. 2A, B, D, E); the internal prong of the clasper in $S$. straminealis is clearly curved inward while it is straight in the new species (Fig. 2A, B, D, E); the medially directed process at the internal base of the clasper is dagger-shaped and long in S. straminealis, but is a pointed triangular, deeply serrate and relatively short structure in S. urmiensis sp. nov. (Fig. 2A, B, D, E); the juxtal arms in the new species are slightly longer and narrower than in S. straminealis; the saccus in S. urmiensis sp. nov. is slightly narrower than that of $S$. straminealis and the anterior tip is nearly pointed (Fig. 2A, D).

Description of male. Head (Fig. 3A, C). Frons conical, covered with pale brown scales, white laterally just next to compound eyes (most of the frontal scales removed); vertex erected, with pale yellowish-cream scales (Fig. 3A); labial palpus porrect, 1.80 times horizontal diameter of com- 

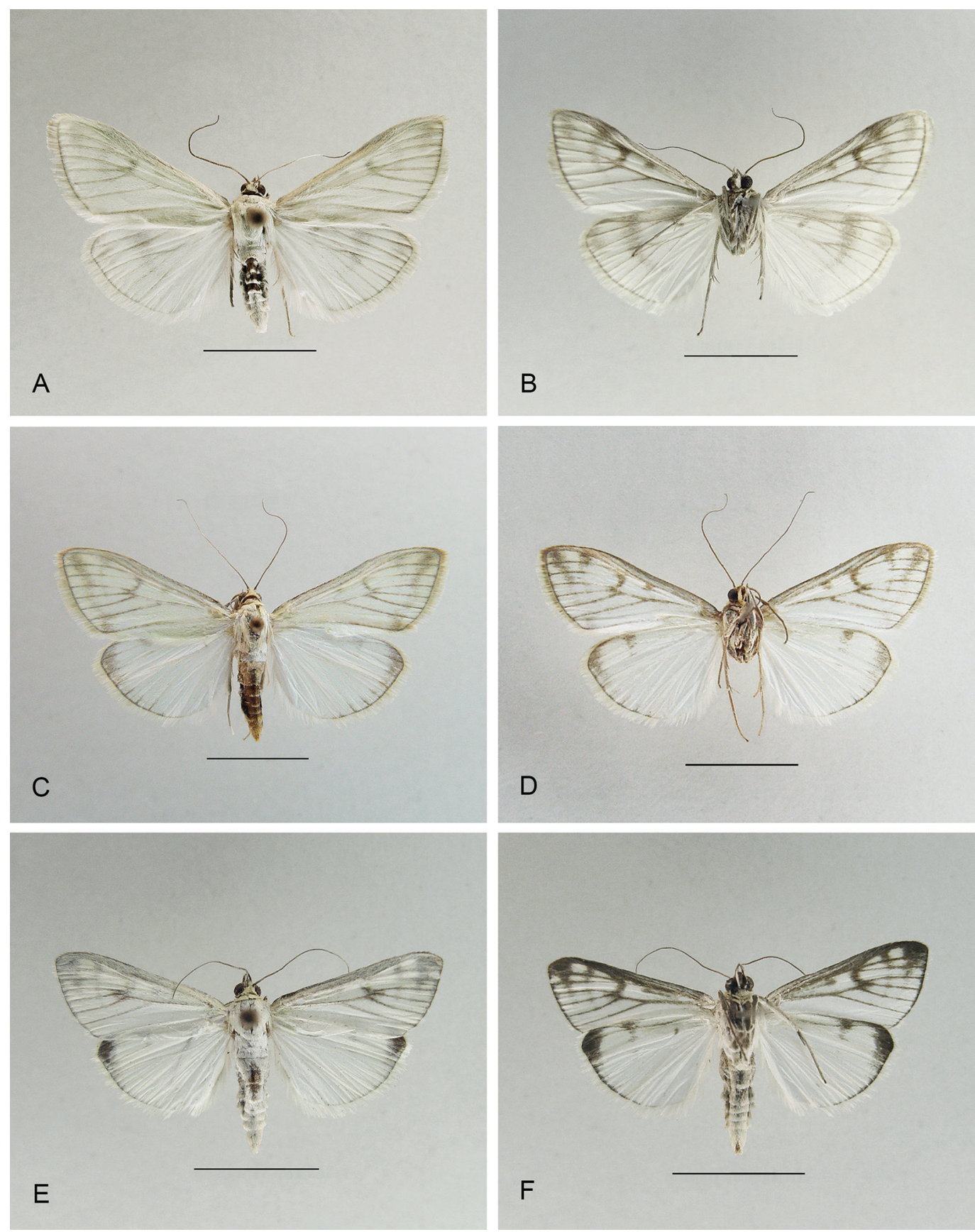

Figure 1. Adult males of Sitochroa spp. A, B Sitochroa urmiensis Alipanah, sp. nov., holotype, C-F S. palealis (Denis \& Schiffermüller). A, C, E Upper side, B, D, F Underside. Scale bars: $10.0 \mathrm{~mm}$.

pound eye, first segment covered with cream scales, second and third segments covered with cream scales ventrally, brown dorsally, apical segment as second except for brown scales dorso-laterally and slightly hanging; maxillary palpus slender, porrect and covered with brown scales; proboscis 

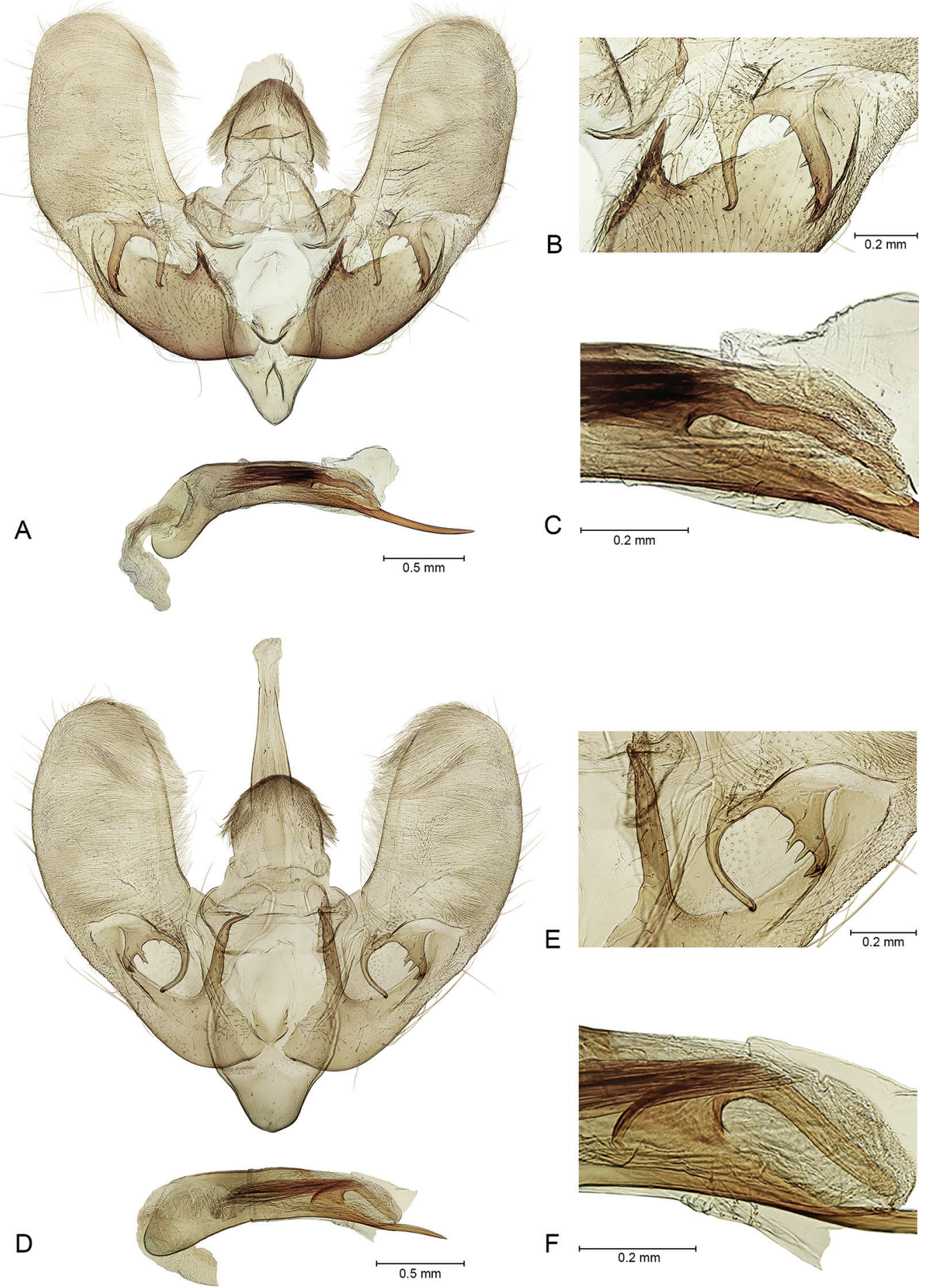

Figure 2. Male genitalia of Sitochroa spp. A-C S. urmiensis Alipanah, sp. nov., holotype, genitalia preparation No. HA-2457, HMIM, D-F S. straminealis (Hampson), genitalia preparation No. HA-2436, HMIM. 

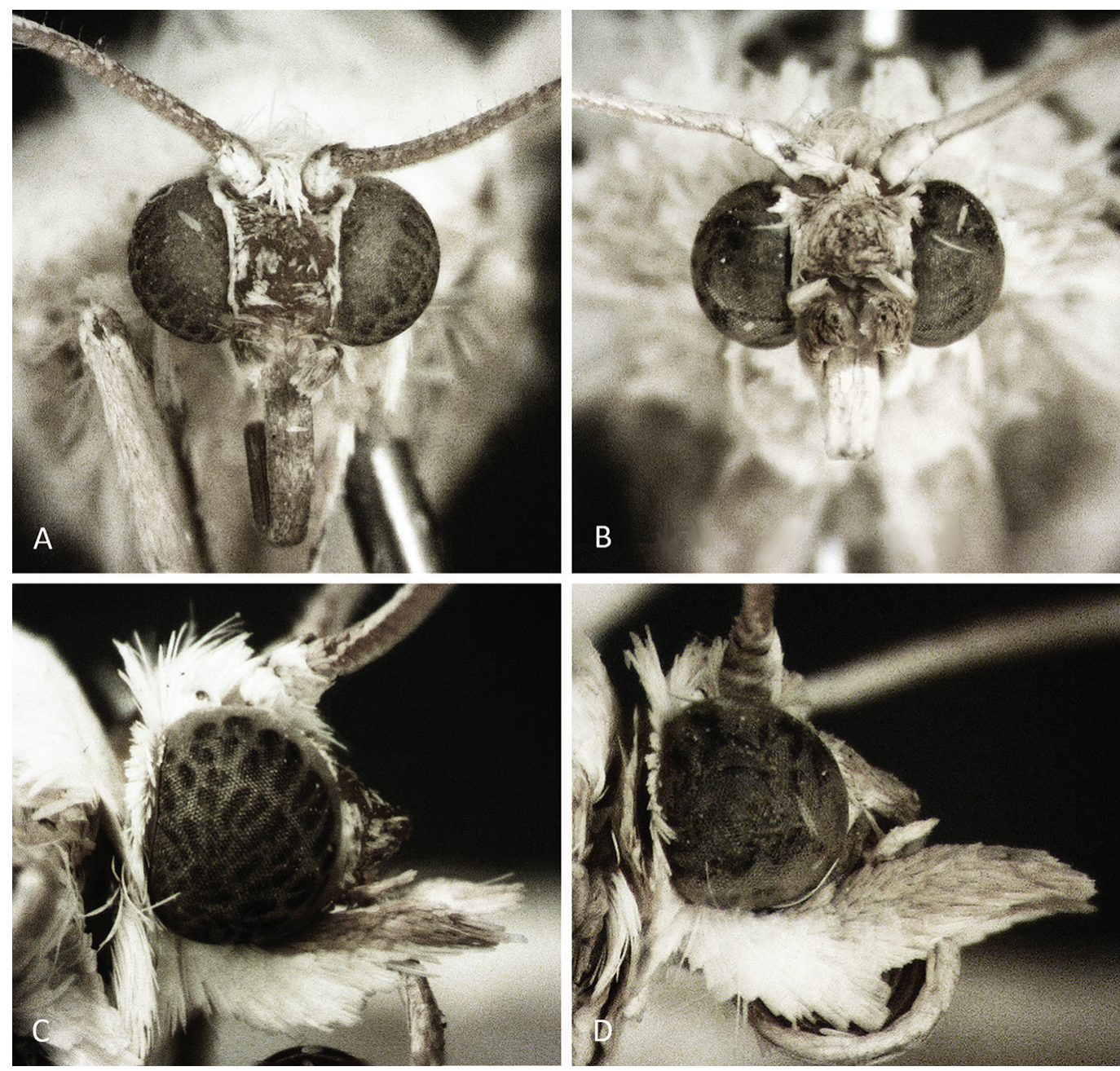

Figure 3. Head of Sitochroa spp. A, C S. urmiensis Alipanah, sp. nov., holotype, male, B, D S. straminealis (Hampson), female. A, B Frontal view, C, D Lateral view.

covered with dark brown scales, paler basally; antennae covered with cream scales dorsally, with a single considerably long seta present on dorsal surface of basal segment; collar yellowish-cream; thorax and tegula yellowish-cream; abdomen cream (Fig. 1A).

Forewing (Fig. 1A, B). Forewing length $15 \mathrm{~mm}$; costa straight, slightly convex towards apex, rounded apically, termen obliquely convex. Ground colour glossy yellowish-cream with pale green tint, with veins and terminal line suffused pale-brownish, a hardly visible pale brown patch near apex, an obscure discoidal spot, and a hardly visible sinuate postmedial line fading away towards dorsum. Underside pale greyish-yellow, with brown costal margin, brown veins and terminal line, a brown sinuate postmedial line thickened towards costa and fading away towards dorsum, an oval pale brown spot near apex, a brown discoidal spot, and a short brown antemedial spot.

Hindwing (Fig. 1A, B). Greyish-yellow, paler than forewing, veins and terminal line with pale-brownish suffusion, a relatively wide medial line extending to two-thirds of the wing, and an 
obscure oval pale brown spot just next to apex. Underside ground colour as that of forewing, veins and terminal line brown, pale brown medial line narrowing and fading away towards dorsum, with small discoidal spot. Fringes of both fore- and hindwings glossy yellowish-cream with very fine light brown medial line.

Male genitalia (Fig. 2A-C). Uncus relatively wide, rounded apically, with some relatively long apical hairs dorso-laterally; tegumen stout, scobinate dorsally; valva broad, rounded apically, with large, arched, clasper adorned with two ventrally directed thorn-like processes, external process serrate ventrally, sinus between prongs of clasper rounded, with deeply serrate, pointed, triangular and relatively large process at internal base of clasper directed medially, and a trapezoidal bladelike structure above clasper pointed internally; juxta deeply V-shaped; saccus elongated triangular (Fig. 2A, B); phallus with ventral thorn-like, straight and relatively long sclerotized process distally, cornuti comprising a bundle of elongate, heavily sclerotized spines and a finger-shaped and wavy sclerotized process (Fig. 2A, C).

Female. Unknown.

Distribution. Iran: West Azarbaijan Province (Orumiyeh or Urmia).

Etymology. The new species is named from the type locality, Urmia.

Biology. Unknown.

Remarks. The studied male of S. urmiensis was collected in 1975. Although several collecting trips have been made by the first author and her colleagues in HMIM to Urmia and Ghasemlu since then, no Sitochroa specimens have been collected again from that locality till now. In spite of the superficial similarities among the single examined S. urmiensis and some other Sitochroa species, the differences in the male genitalia are considerable and the species can easily be distinguished.

\section{Sitochroa palealis (Denis \& Schiffermüller, 1775)}

Figs 1C-F, 4A-D, 5A-D, 6A-G, 7A-C

Loxostege farsalis Amsel, 1950: 246, figs 38, 79; syn. nov.

Material examined. Loxostege farsalis: Holotype, ô, Iran, FARs, Straße Ardekan- Talochosroe, Comé (= Sepidan- Tall Khosrow Rd., Komehr), 2600 m, vii.1937, coll. Brandt (genitalia preparation No. 2936, NHRS-TOBI 000004701), para-

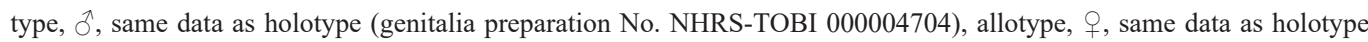
(genitalia preparation No. NHRS-TOBI 000004702).

Other specimens. Iran, Ardebil Prov[INCE]: 1 ㅇ, Sabalān, Qotur Suiee, 38²1'54’N, 4751'43”E, 2276 m, 25.-26. vii.2007, Ālipanāh, Zahiri, Falsafi leg.; East Āzarbāisān Prov[Ince]: 1 ő, Zonuz, 1.ix.1965, Arghand leg. (genitalia

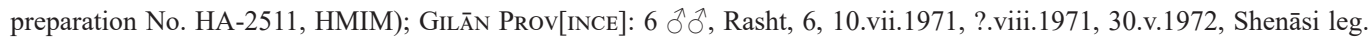
(genitalia preparation No. HA-2453, HMIM), 2 ổ ô, Asālem, Sheykh Mahal, 160 m, 28.-30.vi.1977, Pāzuki, Mortazavihā leg., 2 우, Asālem, Lākudeh, 250 m, 8, 9.vii.2000, Barāri, Mofidi-Neyestānak, Ebrāhimi, Deuve leg., 1 q, Āstārā- Ardebil

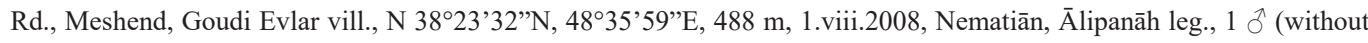
abdomen), Fuman, Gashtrudkhān, 38¹5’15”N, 47²3’52”E, 295 m, 29.vi.2008, Ālipanāh, Nematiān leg.; KoHGILUYEH ANd Boyerahmad Prov [INCe]: 1 ô, Yāsuj, Sisakht, 2250 m, 13.vi.1972, Ebert, Pāzuki leg. (genitalia preparation No. HA-2415, HMIM), 1 † (without abdomen), 15 km SE. Yāsuj, 2050 m, 15.vi.1972, Ebert, Pāzuki leg.; MĀZANDARĀN Prov [INCE]: 1 ô, Bābolsar, 10.ix.1949, Farahbakhsh leg.; RaZavi Khorāsān Prov [INCE]: 1 ô, N. Tandoreh National Park, 56 km after Tivān Ranger St., Dolatshānlu vill. Rd. (km 15), Bābāneyestān, 37³0'14’'N, 5845'01'”E, 1178 m, 6.vi.2016, Ālipanāh, Falsafi leg., 1 ổ, N. Tandoreh National Park (1 km after Alibulāgh Ranger Sta.), 37³3’25’N; 58`38’43”E, 1297 m, 


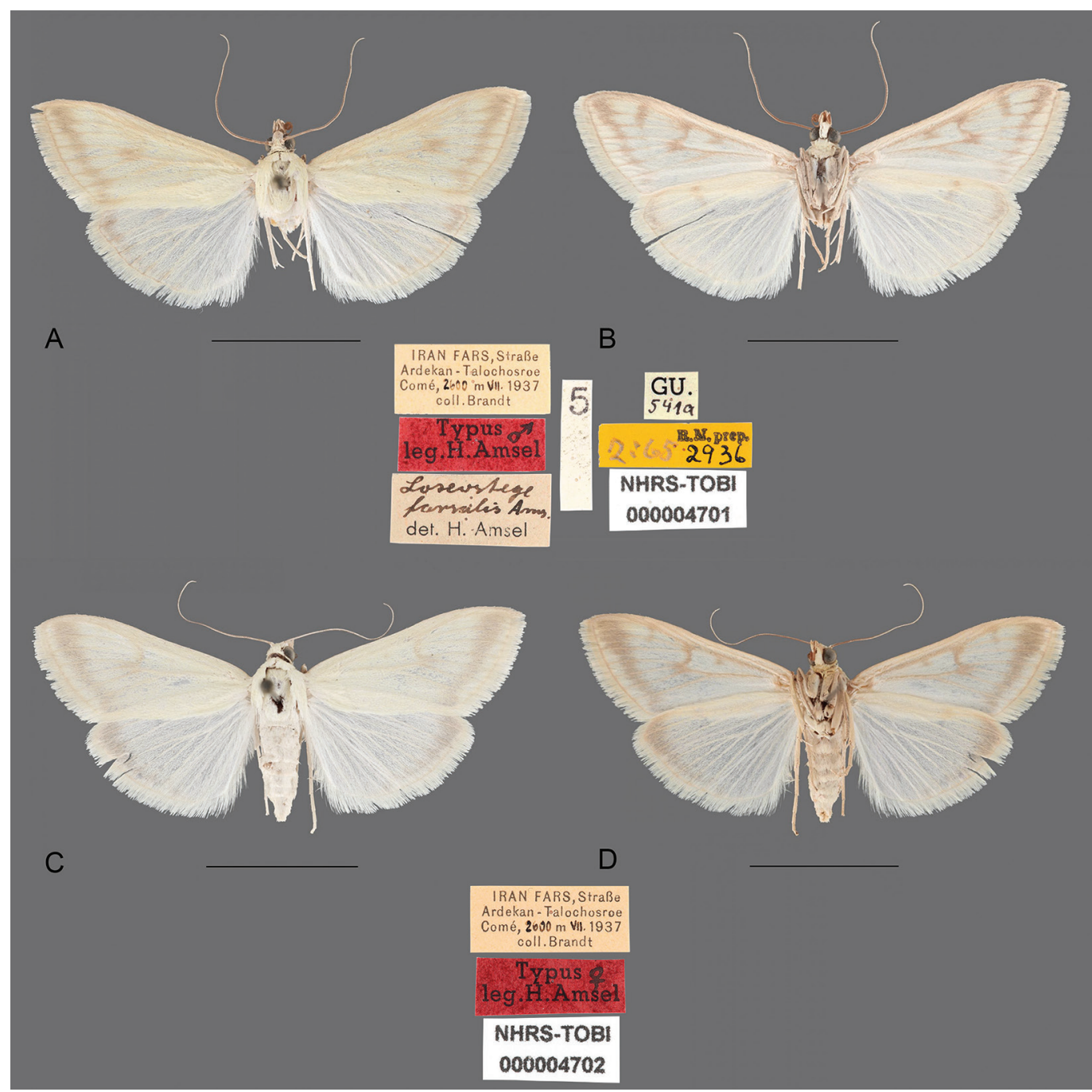

Figure 4. Adults of Loxostege farsalis Amsel syn. nov. A, B Holotype, male, C, D Allotype, female. A, C Upper side, B, D Underside. Scale bars: $10.0 \mathrm{~mm}$.

7.vi.2016, Falsafi, Ālipanāh leg.; South Khorāsān Prov [INCE]: 1 đ 1 q, Tabas, Palm Res. St. \& Adaptaion, 33³5’57’N, 056 54'54”'E, 678 m, 31.v.2016, Ālipanāh, Falsafi leg. (genitalia preparation No. HA-2513, HMIM).

Remarks. Loxostege farsalis was described by Amsel (1950) based on two pairs (as stated by him, two males and two females; but direct examination of the type specimens indicated three males and one female) collected in Iran (Fars Prov.: Comé [= Komehr]). Amsel (1950) recognized the close affinity between S. palealis and L. farsalis in some characteristics of the forewing pattern and male genitalia. According to him (Amsel, 1950), these two species are very similar in forewing pattern, but in L. farsalis the markings of the forewing are weakly expressed so that the marginal (= subterminal) line is hardly visible (Fig. 4A-D). Amsel (1950) also stated that $S$. palealis is always 
bigger than L. farsalis and has a distinct marginal line on the underside of the forewing (Fig. 4B, D) (missing in S. palealis). Regarding male genitalia, Amsel (1950) noted that the uncus of L. farsalis is wider than that of $S$. palealis; the paired processes of the clasper are directed downward in $S$. palealis while being perpendicular to the edge of the valvae in L. farsalis; and the shape of the processes at the internal base of the clasper in these two species is different. Nothing was mentioned about female genitalia (Amsel 1950).

In the present study, we examined $21 \mathrm{~S}$. palealis specimens, including the genitalia of three males and one female. Among this material were a few specimens with weakly expressed markings of the forewing as seen in the L. farsalis syntypes. The latter specimens are slightly larger than the others, with hardly visible markings in the hindwings (Fig. 1C, D), but their genitalia are typical of $S$. palealis. A careful examination of the type specimens of $L$. farsalis revealed that they also have a distinct subterminal line (the marginal line stated by Amsel (1950)) on the upper- and underside of the forewing, although it is weakly expressed in L. farsalis. These type specimens are also similar to specimens of $S$. palealis in the shape of frons, labial palpi and cover scales of head (Fig. 5A-D).

We dissected two paratypes (a male and the female) of L. farsalis, and compared their genitalia with those of specimens of $S$. palealis. The results showed that the female genitalia are exactly the same (Fig. 7A-C). Almost the same result was found for the male genitalia (Fig. 6A-G). The shape and width of the uncus are nearly the same (Fig. 6A, C) and the shape of processes at the internal base of the clasper and the paired clasper processes are similar (Fig. 6A-F). Amsel (1950) stated that the paired processes of the clasper are directed downward in S. palealis, but it is not known if Amsel had actually examined the type specimens of $S$. palealis. We didn't have access to the type specimens of S. palealis. However, based on Solis (2010: 509) and Slamka (2013: 154), these processes are perpendicular to the edge of the valvae in S. palealis, as is the case in the $L$. farsalis male paratype dissected. According to Hannemann (1964), the holotype of S. palealis is "vernichted" (= destroyed). Also, as stated by Horn et al. (1990), the type material of S. palealis was presumably burned with the rest of the Denis \& Schiffermüller collection in the natural history museum of Wien in 1848 . We are not aware of any neotype designation.

In the holotype of L. farsalis, the phallus was not extracted from the remaining parts of the genitalia and the latter were not well cleaned. Because the shape of the phallus is not clearly recognizable in this preparation, a male paratype was dissected and examined. The shape of its phallus is very similar to that of our dissected specimens of $S$. palealis, except that the distal process of the phallus is slightly longer and more distinctly curved upward (Fig. 6A) compared with S. palealis (Fig. 6C, G) (see also Solis (2010) and Slamka (2013)). The straight distal process of the phallus in American populations of S. palealis figured by Solis (2010: 509) differs from the nearly curved process in our examined specimens of $S$. palealis and paratype of L. farsalis, as well as slight difference in the length of this process among these specimens, may indicate that this character is slightly variable among different populations.

The sinus between the prongs of the clasper on the valvae of $S$. palealis is mostly without dentation (Fig. 6E, F), but in some specimens a small dent is visible in this area (Fig. 6D). The same is true for L. farsalis, as in the examined paratype there was one dent at the edge of the sinus in each valva (Fig. 6A), and in the holotype one valva has no dent at the edge of this sinus (Fig. 6B). In both species, there is also a variation in the length of the external prong of the clasper. In the holotype of $L$. farsalis (Fig. 6B), the external prong is longer when compared with that of the paratype (Fig. 6A). Similarly, in S. palealis, the specimens collected in Rasht (Fig. 6F) have a longer external prong than that of specimens collected in Zonuz and Yasuj (Fig. 6C-E). 

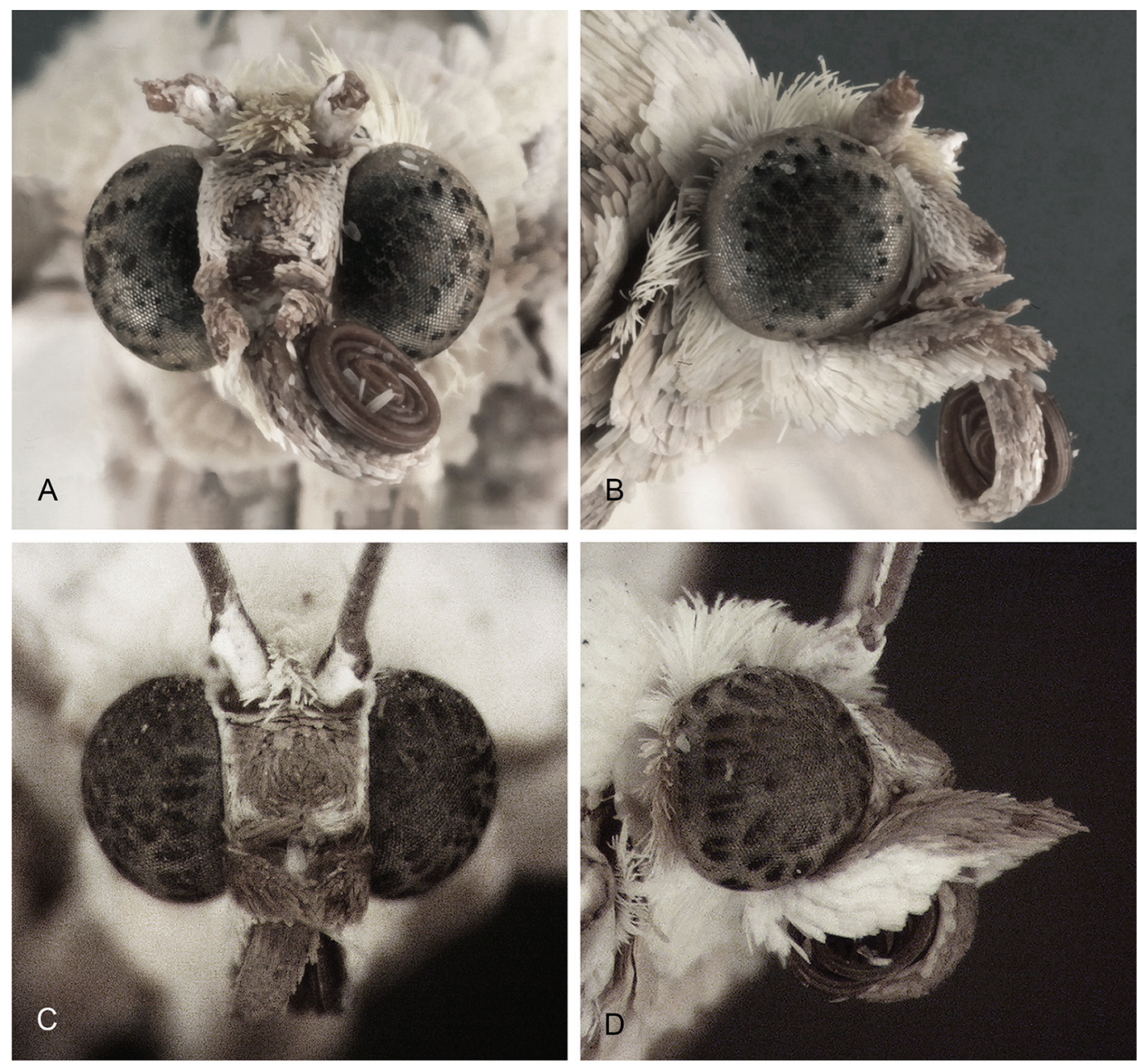

Figure 5. Head. A, B Loxostege farsalis Amsel syn. nov., holotype, male, C, D Sitochroa palealis (Denis \& Schiffermüller), male. A, C Frontal view, B, D Lateral view.

Therefore, based on our analysis, L. farsalis is regarded as a junior synonym of S. palealis.

Distribution. Widespread in the Palaearctic, but rare in southern Scandinavia and only an occasional migrant in England, India (Slamka, 2013), and Iran [Fars Province: Come (=Komehr), Gilan Province: Tahergourabe; Golestan Province: Golestan National Park (Ghaleh Palangan)] (Amsel 1950, 1959; Wieser et al. 2001).

Sitochroa malekalis (Amsel, 1950), comb. nov.

Figs 8A, B, 9A-C, 10A, B, D

Loxostege malekalis Amsel, 1950: 245-246, figs 37, 78.

Material examined. Iran, FĀrs Prov [INCE]: 2 + ,, 50 km Khonj- Lar Rd., 920 m, 14.iv.1975, Borumand leg. (genitalia preparation No. HA-2512, HMIM), 1 +, 50 km Lar- Jahrom Rd., 890 m, 13.iv.1975, Borumand leg.; TEHRĀN Prov [INCE]: 

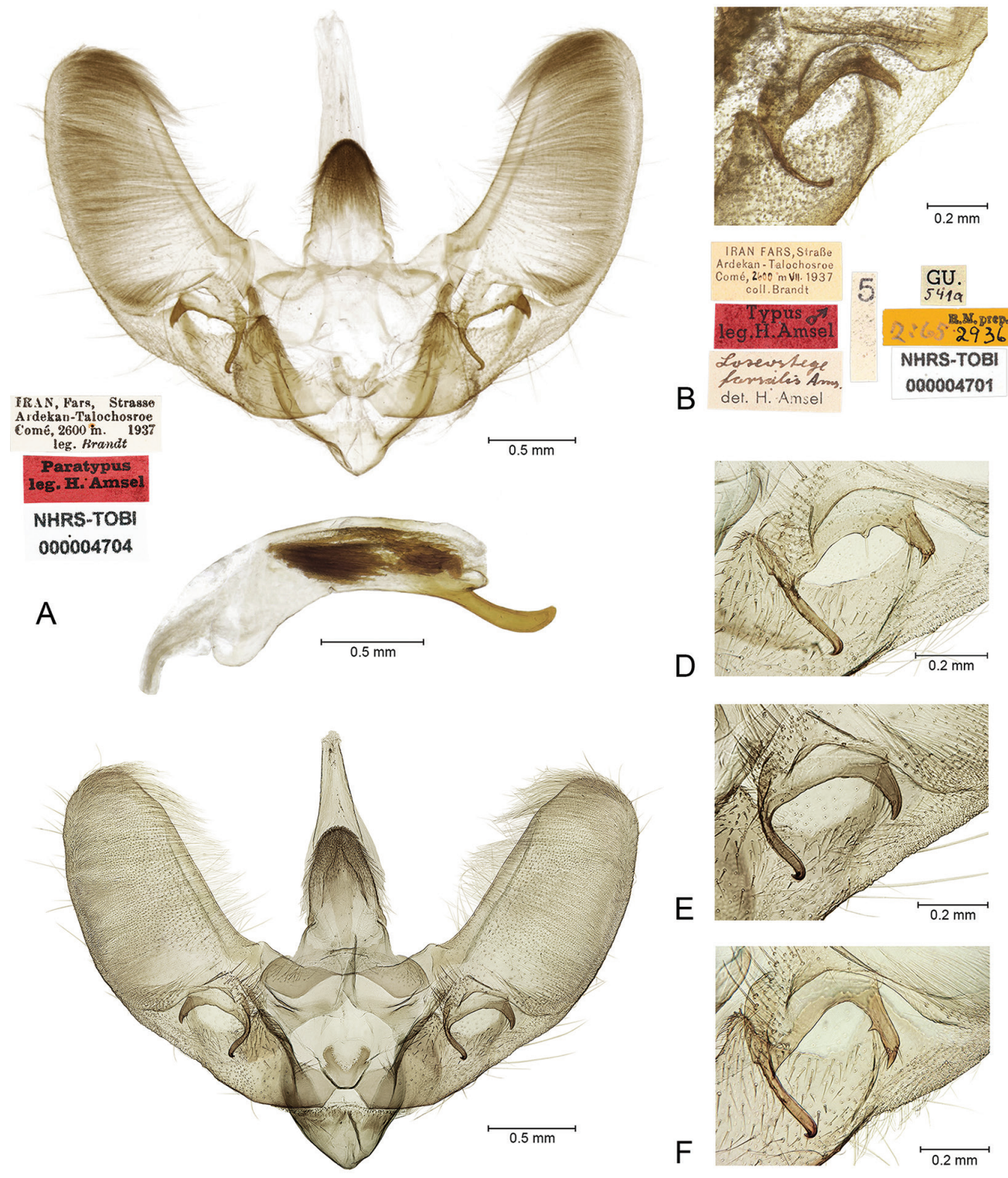

D
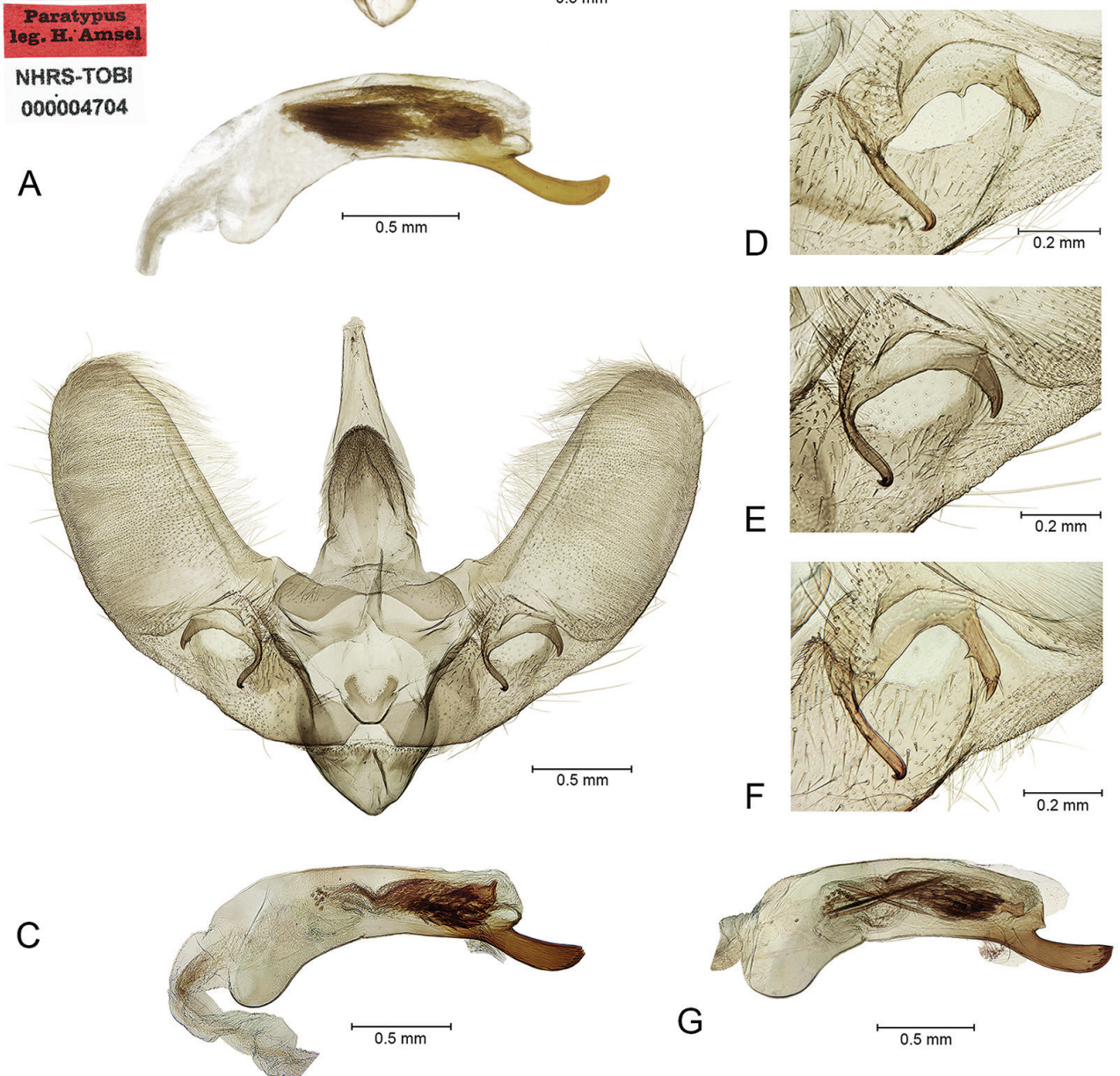

Figure 6. Male genitalia. A, B Loxostege farsalis Amsel syn. nov. A Paratype, genitalia preparation No. NHRS-TOBI 000004704, B Holotype, genitalia preparation No. 2936, NHRS-TOBI 000004701, C-G Sitochroa palealis (Denis \& Schiffermüller), C, E genitalia preparation No. HA-2415, HMIM, D genitalia preparation No. HA-2511, HMIM, F, G genitalia preparation No. HA-2453, HMIM. 

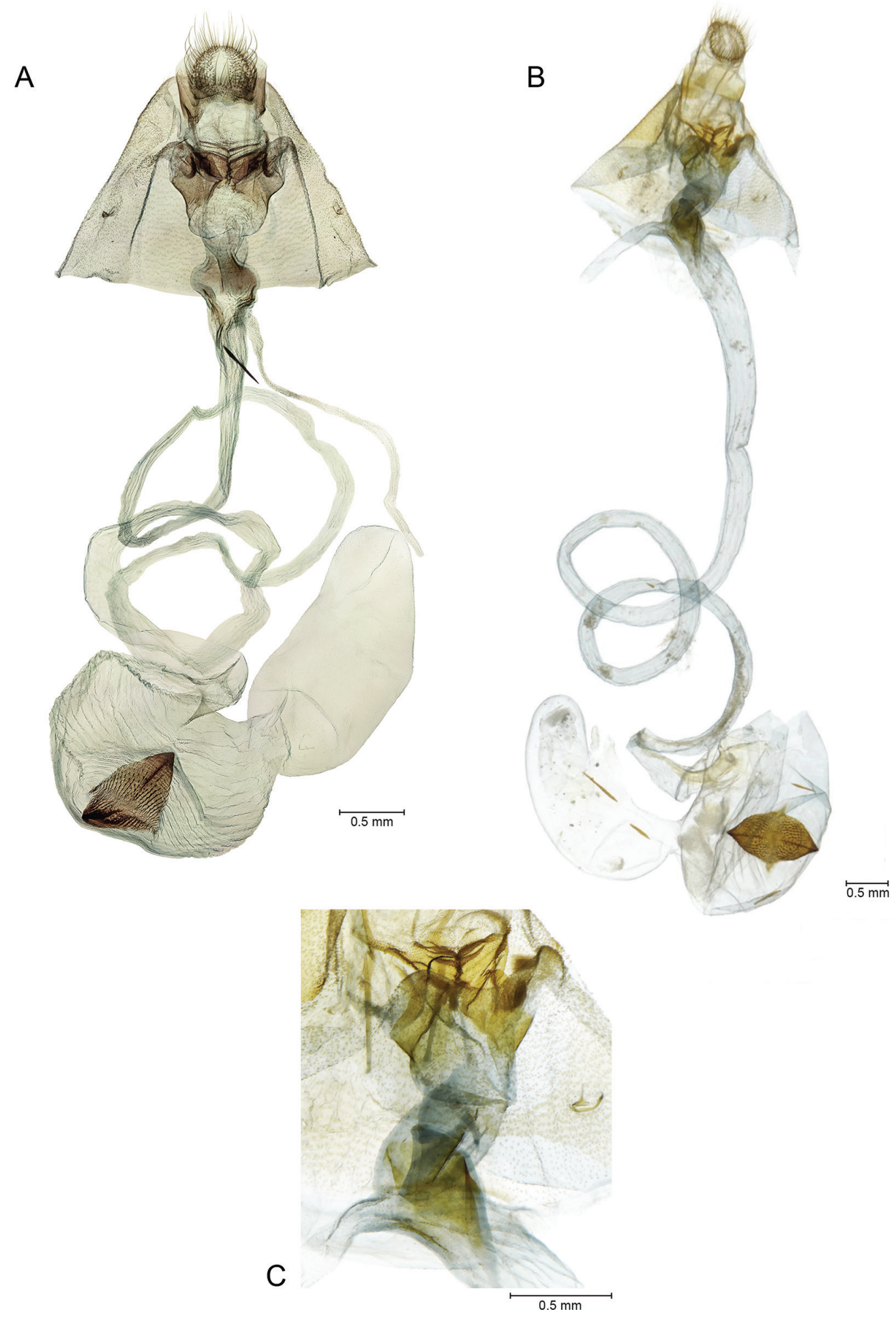

Figure 7. Female genitalia. A Sitochroa palealis (Denis \& Schiffermüller), genitalia preparation No. HA-2513, HMIM, B, C Loxostege farsalis Amsel syn. nov., allotype, genitalia preparation No. NHRS-TOBI 000004702. 
1 + Tehrān, Evin, 26.v.1971, no collector given, 1 \&, Tehrān, Evin, 1600 m, 22.vi.1972, no collector given (genitalia preparation No. 158, HMIM).

Turkmenistan, 1 O̊, W. Kopet Dagh, Parchai, 400 m, 2.v.1996, Z. Klyutschko leg. (genitalia preparation No. 5567 Asb).

Note. Loxostege malekalis was described by Amsel (1950) based on a single male collected in Takht-e Malek (Sistan and Baluchestan Province) at the beginning of April 1938, and since then the female remained undescribed. During our study, five females were found in the HMIM with the same wing pattern and external characteristics as the male holotype based on the original description, but not examined. They are also externally very similar to the single examined male specimen collected in Kopet Dagh. Because of this superficial similarity, the females are here considered conspecific with L. malekalis and described.

Following a careful examination, the male genitalia of L. malekalis possess the main diagnostic characters of the genus Sitochroa, i.e. a biramous clasper and the presence of a distal sclerotized process at the apex of the phallus. Therefore, this species is here transferred to the genus Sitochroa.

Diagnosis. Sitochroa malekalis is similar to S. palealis in female genitalia but can be distinguished from the latter by the weakly sclerotized antrum and narrower medial notch at the posterior margin of the seventh abdominal sternite (Figs 7A-C, 10A, B). Moreover, S. palealis has a heavily wrinkled, sclerotized lamella postvaginalis (Fig. 7A-C) while in S. malekalis it is hardly sclerotized with less visible wrinkles (Fig. 10A, B). These two species also differ from each other in wing pattern (Figs 1C-F, 8A, B) and male genitalia structure (Figs 6A-G, 10D).

There are similarities in the female genitalia between $S$. malekalis and $S$. straminealis owing to the presence of a distinct upturned curvature at the posterior end of the ductus bursae, and an elongate sclerotized structure next to it (Fig. 10A-C), the shape of the corpus bursae and appendix bursae, and the hardly sclerotized lamella postvaginalis (Fig. 10A-C). However, they are very different from each other mainly in the more sclerotized funnel-shaped antrum of $S$. straminealis compared to the less sclerotized trapezoidal antrum in $S$. malekalis, and nearly smooth posterior margin of seventh abdominal sternite of $S$. straminealis compared to that of $S$. malekalis with deep medial notch (Fig. 10A-C).

The male genitalia $S$. malekalis and $S$. straminealis are similar to each other in having a long sclerotized process at the internal base of each clasper. However, in S. malekalis the two processes are divergent, less sclerotized, and with rounded apices (Fig. 10D) while in S. straminealis they are nearly parallel (in some specimens slightly curved inward), more sclerotized and pointed apically (Fig. 2D, E). Moreover, in both species the uncus is relatively wide (Figs 2D, 10D) and the phallus has a narrow, elongate distal sclerotized process (Figs 2D, E, 10D), although in S. malekalis the vesica has only one slender cornutus compared with the three cornuti in S. straminealis (Fig. 2D, F). These two species are also very different from each other in wing pattern (Fig. 8A-D).

The close external resemblance of $S$. malekalis to Loxostege phaeoneuralis (Hampson, 1900) was mentioned by Amsel (1950). However, these two species are very different from each other in genitalia structure.

Description of female. Head (Fig. 9A-C). Frons with bluntly pointed cone (Fig. 9B, C), covered with brown to pale brown scales and sometimes cream scales admixed with pale brown scales, paler laterally next to the compound eyes in some specimens; vertex with erect cream scales; with few ochre scales behind compound eye; labial palpus porrect with drooping apical segment (Fig. 9B, C), nearly twice $(\mathrm{n}=4)$ horizontal diameter of compound eye, second segment longest, apical segment one-third of second segment $(n=1)$, first segment covered with cream scales, sec- 

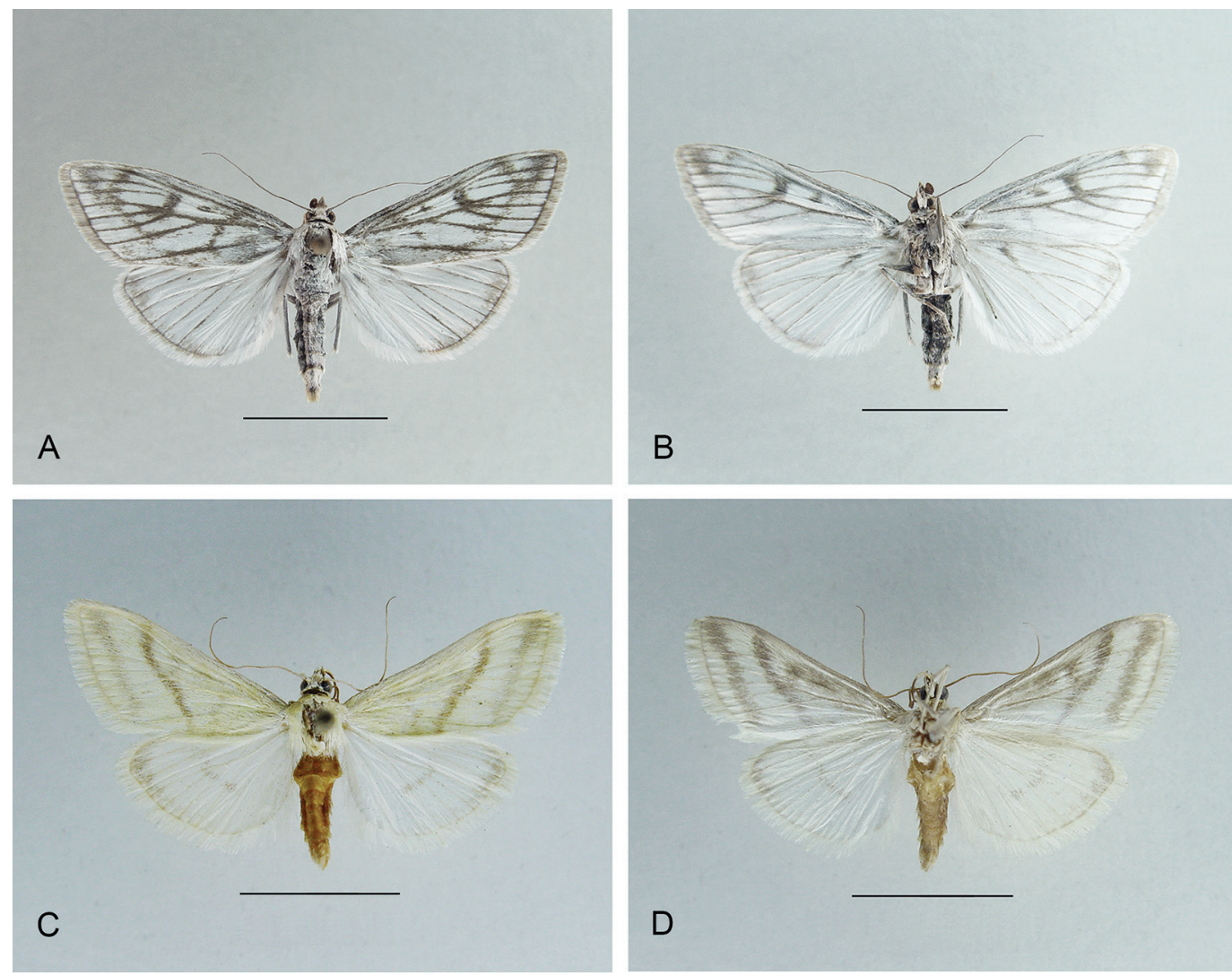

Figure 8. Adults of Sitochroa spp. A, B S. malekalis (Amsel) comb. nov., female, C S. straminealis (Hampson), female. A, C Upper side, B, D Underside. Scale bars: $10.0 \mathrm{~mm}$.

ond and third segments covered with cream scales ventrally, brown to ochreous-brown dorso-laterally, in one specimen cream scales admixed with brown scales dorsally; proboscis mostly covered with cream to dirty-cream scales dorsally, in one specimen admixed with ochreous-brown scales; antennae covered with pale brown scales dorsally, in one specimen with cream scales dorsally, with a single considerably long seta present on dorsal surface of basal segment; collar cream, admixed with few pale ochreous-brown scales (Fig. 9A-C); thorax and tegula cream, admixed with pale brown scales anteriorly, cream posteriorly; abdomen dirty-cream to pale brown (Fig. 8A).

Forewing (Fig. 8A, B). Elongate, slightly rounded apically, with costa slightly convex at distal one-third and obliquely rounded termen, with length of $14.50-16.50 \mathrm{~mm}(\overline{\mathrm{x}}=15.80 \mathrm{~mm}, \mathrm{n}=5)$; upper side glossy cream, veins and terminal line with brown suffusion, a curved brown medial line present, a strongly curved brown postmedial line crenate towards dorsum between veins $\mathrm{Cu}_{1}, \mathrm{Cu}_{2}$, $\mathrm{A}_{1+2}$ and dorsum, with brown discoidal spot, a brown antemedial spot and a relatively broad brown subterminal line thickened towards costa and crenate towards the dorsum, sometimes fading away towards dorsum, fringes dirty-cream to pale brown, with a median pale brown band; underside same as upper side, with antemedial, postmedial and subterminal lines less visible than on upper side, except for the thickened pale brown costal tip of the subterminal line.

Hindwing (Fig. 8A, B). Upper side creamy-white, veins and terminal line with pale brown suffusion except for cream suffusion on anal veins, with relatively wide brown to pale brown sub- 

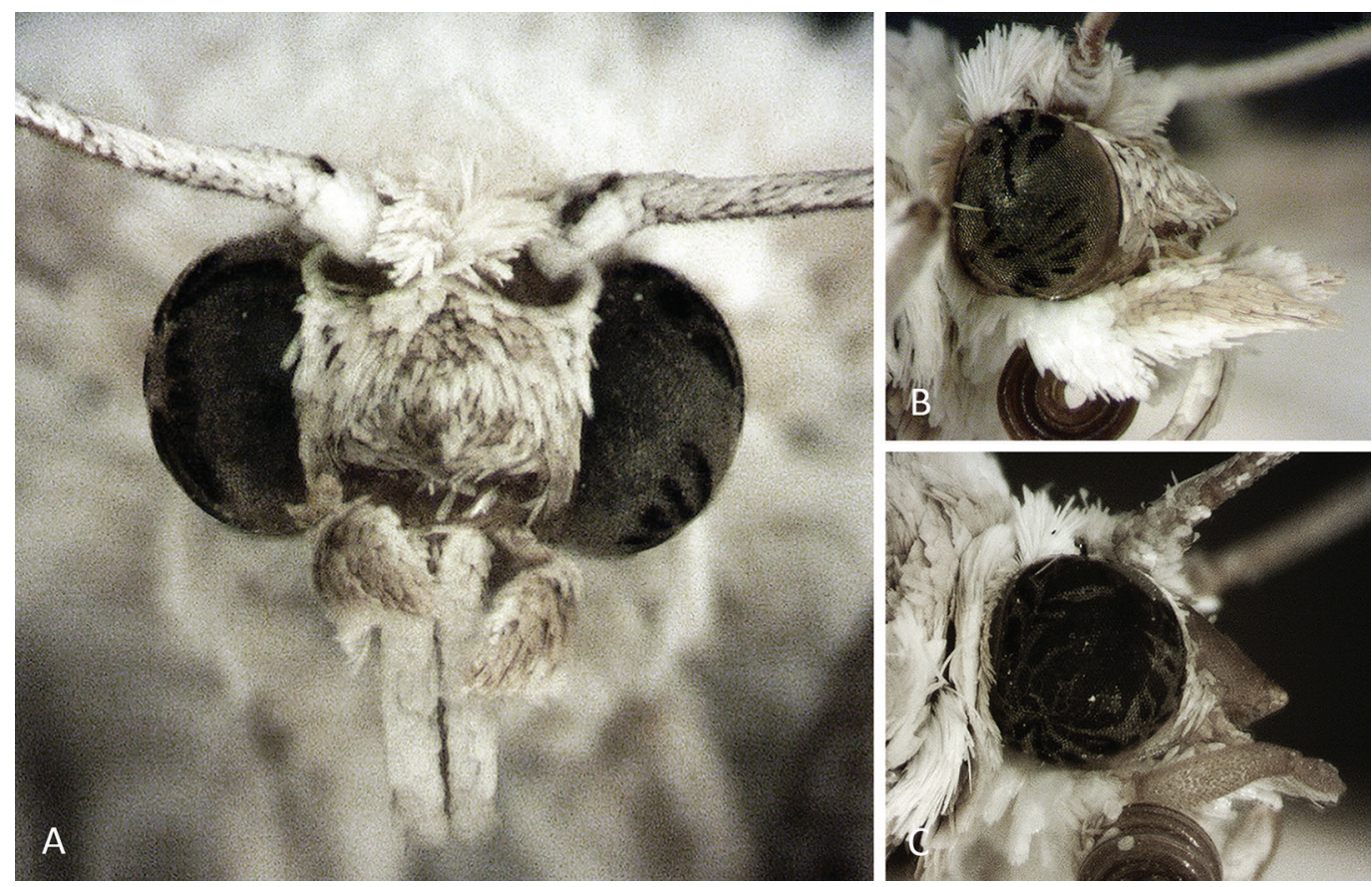

Figure 9. Head of Sitochroa malekalis (Amsel) comb. nov., female. A Frontal view, B, C Lateral view.

terminal line, medial line hardly visible, fringes dirty-cream with hardly visible median pale brown band; underside same as upper side.

Female genitalia (Fig. 10A, B). Papillae anales of moderate length and width, slightly narrowed anteriorly; apophyses posteriores slightly shorter than apophyses anteriores; posterior margin of seventh abdominal sternite with deep medial notch, with rounded edges, and setae of moderate sizes (nearly all removed during slide preparation); lamella postvaginalis very slightly sclerotized with hardly visible wrinkles; ostium bursae rounded; antrum nearly membranous, large, trapezoidal and slightly constricted medio-laterally, with small funnel-shaped appendage anteriorly (Fig. 10A, B); ductus bursae long, partly twisted, with posterior end widened and partially wrinkled just behind antrum, an elongate sclerotized structure beyond widened area and distinct upturned curvature next to it, with deep kinks at anterior end; ductus seminalis emerging from slightly beyond intersection of ductus bursae and antrum; corpus bursae ovoid, thick-walled, wrinkled, with relatively large rhomboid signum, appendix bursae extending from corpus bursae ventro-apically, round to ovoid when fully inflated (Fig. 10A).

Distribution. Iran: Tahte Malek (= Takht-e Malek, Sistan and Baluchestan Province) (Amsel 1950) (see also material examined for Iranian specimens), Turkmenistan (current study).

\section{Acknowledgements}

Our special gratitude is expressed to Shahab Manzari (Iranian Research Institute of Plant Protection, Tehran, Iran) for his linguistic revision of the manuscript and valuable comments. Financial support was provided to H. Alipanah for the "Pyraustinae of Iran" project (Iranian Research Institute of Plant Protection). 


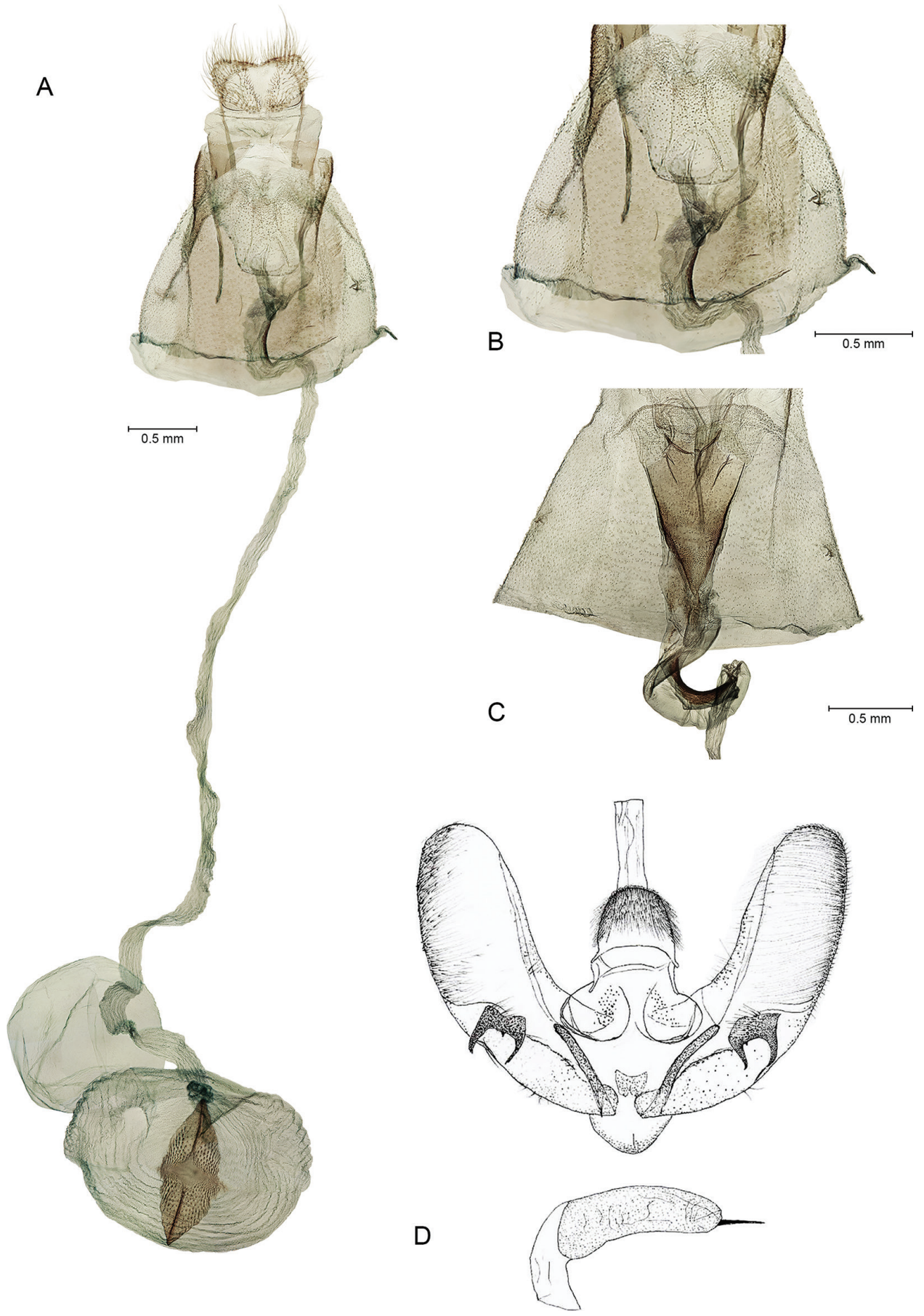

Figure 10. Genitalia of Sitochroa spp. A, B, D S. malekalis (Amsel) comb. nov.: A Female genitalia, genitalia preparation No. HA-2512, HMIM, B Eighth segment, genitalia preparation No. HA-2512, HMIM, D Male genitalia, genitalia preparation No. 5567 Asb., C Eighth segment of S. straminealis (Hampson), female, genitalia preparation No. HA-2437, HMIM. 


\section{References}

Amsel HG (1950) Die Microlepidopteren der Brandt'schen Iran-Ausbeute. 2. Teil. Arkiv för Zoologi (N.S.), Stockholm (ser. 2) 1(17): 223-257.

Amsel HG (1959) Microlepidoptera aus Iran. (Ergebnisse der Entomologischen Reisen Willi Richter, Stuttgart, im Iran 1954 und 1956-Nr.25). Stuttgarter Beiträge zur Naturkunde 28: 1-38.

Amsel HG (1961) Die Microlepidopteren der Brandt'schen Iran-Ausbeute. 5. Teil. Arkiv för Zoologi (N.S.), Stockholm (ser. 2), 13(17): 323-445. [pls. 1-9]

Chen K, Liu Q, Jin J, Zhang D (2019) Revision of the genus Emphylica Turner, 1913 based on morphology and molecular data (Lepidoptera, Crambidae, Pyraustinae). ZooKeys 836: 113-133. https://doi. org/10.3897/zookeys.836.32796

Christoph H (1876) Sammelergebniss aus Nordpersien, Krasnowodsk in Turkmenien und dem Daghestan. Horae Societatis Entomologicae Rossicae 12: 181-299.

Clarke JFG (1941) The preparation of slides of the genitalia of Lepidoptera. Bulletin of the Brooklyn Entomological Society 36: 149-161.

Hannemann HJ (1964) Kleinschmetterlinge oder Microlepidoptera. II. Die Wickler (s. 1.) (Cochylidae und Carposinidae) Die Zünslerartigen (Pyraloidea) in «Die Tierwelt Deutschlands», 50: 1-401. [296 fig., 22 pl.]

Horn W, Kahle I, Friese G, Gaedike R (1990) Collectiones entomologicae, part $1+2$. Akademie der Landwirtschaftswissenschaften, Berlin, 573 pp.

Hübner J (1816-1826) [imprint “1816”]: Verzeichniß bekannter Schmettlinge [sic]. bey dem Verfasser zu finden, Augsburg. (Verzeichniß) [1]-[3]-4-6-[7]-8-431, (Anzeiger) [1]: 2-72.

Kristensen NP (2003) Skeleton and muscles: adults. In: Kristensen NP (Ed.) Lepidoptera, Moths and Butterflies 2, Morphology, Physiology and Development. Handbook of Zoology (Vol. IV. Part 36). Walter de Gruyter, Berlin/New York, 45-145. https://doi.org/10.1515/9783110893724.39

Lederer J (1869) Verzeichniss der von Herrn Jos. Haberhauer bei Astrabad in Persien gesammelten Schmetterlinge. Horae Societatis Entomologicae Rossicae 6: 6-93. [5 pls.]

Mally R, Hayden JE, Neinhuis C, Jordal BH, Nuss M (2019) The phylogenetic systematics of Spilomelinae and Pyraustinae (Lepidoptera: Pyraloidea: Crambidae) inferred from DNA and morphology. Arthropod Systematics and Phylogeny 77(1): 141-204. http://doi.org/10.26049/ASP77-1-2019-07

Munroe EG (1976) Pyraloidea Pyralidae comprising the subfamily Pyraustinae tribe Pyraustini. 13.2A (part), Pp. 1-78, pls 1-4, A-H; 13.2B (conclusion), Pp. 79-150, pls 5-9, J-U, pp. xiii - xvii. In: Dominick RB, Dominick T, Ferguson DC, Franclemont JG, Hodges RW, Munroe EG (Eds) The Moths of America North of Mexico. E.W. Classey Ltd. and The Wedge Entomological Research Foundation, London.

Nuss M, Landry B, Mally R, Vegliante F, Tränkner A, Bauer F, Hayden J, Segerer A, Schouten R, Li H, Trofimova T, Solis MA, De Prins J, Speidel W (2003-2019) Global Information System on Pyraloidea. www. pyraloidea.org [Accessed December, 5, 2019]

Robinson GS (1976) The preparation of slides of Lepidoptera genitalia with special reference to the Microlepidoptera. Entomologist's Gazette 27: 127-132.

Slamka F (2013) Pyraustinae \& Spilomelinae. Pyraloidea of Europe 3: 1-357.

Solis MA (2010) Sitochroa palealis: A Palearctic pyraustine moth (Lepidoptera: Pyraloidea: Crambidae) newly introduced to North America. Proceedings of the Entomological Society of Washington 110(2): 504-515. https://doi.org/10.4289/07-089.1

Wieser C, Humer P, Stangelmaier G (2001) Schmetterlinge (Lepidoptera). In: Gutleb B, Wieser C (Eds) Nordiran. Ergebnisse einer Zoologischen Exkursion. Carinthia II (Klagenfurt) 192(112): 52-81. 